\title{
Comparative study of quality of Random Donor Platelet Concentrates Prepared from in-house collection and outdoor blood donation camps
}

\author{
Trivedi $\mathrm{NS}^{1^{*},}$ Kothari $\mathrm{F}^{2}$,Dighe $\mathrm{MP}^{3}$ \\ 1. 2nd year Resident, Immunohaematology and blood transfusion, SSG Hospital, Baroda, Gujarat \\ 2. Associate Professor, Immunohaematology and blood transfusion, SSG Hospital, Baroda, Gujarat \\ 3. HOD, Immunohaematology and blood transfusion, SSG Hospital, Baroda, Gujarat
}

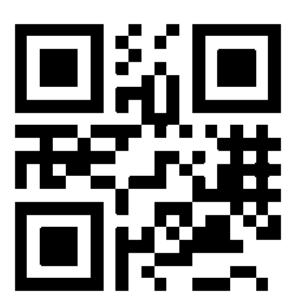

\begin{abstract}
Background: Platelet transfusion is an accepted vital treatment method in patients with bleeding disorders. The quality of platelet concentrate is affected by preparation method and storage conditions including duration of storage, type of storage containers. Methods: The study was conducted in blood bank, S.S.G. Hospital, Vadodara during period of September 2019 to October 2019. Platelet products were prepared by PRP method according to SOPs approved by AABB .The sample size was 100, 50 from in house collection and 50 from outdoor blood donation camps. Sampling was done randomly and all the healthy individuals who donated
\end{abstract} blood fulfilling inclusion criteria were included in the study. Results: Platelet concentrates prepared from whole blood collected from in house collection and outdoor camps were compared for various quality determinants such as platelet count, $\mathrm{pH}$,swirling, WBC count. These were compared with the standards by AABB. The obtained data were conducted in terms of student t-test the $\mathrm{p}<0.05$ was considered statistically significant. $80 \%$ of platelet concentrates prepared from in house collection showed platelet count $>5.5 \times 10^{1^{\circ}}$ $.60 \%$ of platelets prepared from outdoor camps showed $\mathrm{pc}<5.5 \times 10^{10}$. This suggests that approximately half of the platelet units which were prepared from the outdoor blood donation camps may not have expected therapeutic outcomes on recipients. The WBC count of these deficient platelets were higher $\left(>5 \times 10^{8}\right)$ and $\mathrm{pH}$ was significantly higher (>6.0). Conclusion: Our findings shows that quality of platelets and storage conditions plays an important role in quality of platelet units.

Key words: AABB, WBC count, Platelets

*Corresponding Author

Dr. Nandini S.Trivedi

E-mail id: trivedinandini3693@gmail.com

Copyright: This is an open-access article distributed under the terms of the Creative Commons Attribution license which permits unrestricted use, distribution, and reproduction in any medium for non-commercial use (Non Commercial, or CC-BY-NC) provided the original author and source are credited.

\section{INTRODUCTION}

Platelet transfusion is an accepted vital treatment method in patients with bleeding disorders. The quality of platelet concentrate is affected by preparation method and storage conditions including duration of storage, type of storage containers. Platelet transfusions are mainly used in thrombocytopenic patients most commonly as a result of myelosuppressive therapy, increased consumption as in disseminated intravascular coagulopathy (DIC), and aplastic anemia. ${ }^{1}$

\section{MATERIALS AND METHODS}

The study was conducted in blood bank, S.S.G. Hospital, Vadodara during period of September 2019 to October 2019.Platelet products were prepared by PRP method according to SOPs approved by AABB .At SSGH, the platelet concentrates are prepared from random whole blood donors and platelet concentrates are separated from platelet rich plasma derived from these donors..The sample size was 100,50 from in house collection and 50 from outdoor blood donation camps. Sampling was done randomly and all the healthy individuals who donated blood fulfilling inclusion criteria were included in the study. The recommended shelf life of platelets concentrates is 5 days stored at $22 \pm 2^{\circ} \mathrm{C}$ with continuous agitation. It is known that platelets undergo various changes immediately after they are collected, during processing, storage and even when being administered to the patient. This may affect the effective dosage that a patient receives. ${ }^{2}$ In the laboratory the platelet quality can be assessed by using several parameters (swirling, volume, platelet count and WBC count per bag and $\mathrm{pH}$ changes). ${ }^{3}$ Most of these parameters asses in-vitro platelet function. Each concentrate was then assigned another identification number for the purposes of the study. The concentrates were then weighed and 
the volume determined. The sealed pilot tube was cut with sterile scissors and $1 \mathrm{ml}$ of the unit drawn into two EDTA $75 \times 15 \mathrm{~mm}$ tubes. The tube was then resealed using a bag sealer and released for patient use. The samples were transported to the laboratory for analysis. Platelet count, residual WBC count was determined by Coulter ${ }^{\circledR}$ AcTTM5 Diff Hematology Analyzer. The $\mathrm{pH}$ was determined by an automated Bayer BG analyzer Rapidlab 348 model located at the intensive care unit, SSGH. This instrument determines $\mathrm{pH}$ based on respective electrodes. Blood collected from outdoor blood donation camps were kept in thermocol boxes with ice containers. There was no temperature regulation or ambient temperature measurements and blood collected from indoor donation were kept at standard room temperature $\left(22-26^{\circ} \mathrm{C}\right)$ with temperature regulation.

\section{RESULTS}

Platelet concentrates prepared from whole blood collected from in house collection and outdoor camps were compared for various quality determinants such as platelet count, $\mathrm{pH}$,swirling , WBC count. These were compared with the standards by AABB. The obtained data were conducted in terms of student t-test the $\mathrm{p}<0.05$ was considered statistically significant. $80 \%$ of platelet concentrates prepared from in house collection showed platelet count $>5.5 \times 10^{10}$. $60 \%$ of platelets prepared from outdoor camps showed $\mathrm{pc}<5.5 \times 10^{10}$. This suggests that approximately half of the platelet units which were prepared from the outdoor blood donation camps may not have expectedtherapeutic outcomes on recipients. The WBC count of these deficient platelets were higher $\left(>5 \times 10^{8}\right)$ and $\mathrm{pH}$ was significantly higher $(>6.0)$.

Table 1: Comparison of platelet concentrates with platelet count

\begin{tabular}{|l|l|l|}
\hline & Category 1 & Category 2 \\
\hline Platelet count & Pc $>5.5$ & Pc $<5.5$ \\
\hline WBC count & $780 \pm 450$ & $304 \pm 240$ \\
\hline pH & $6.89 \pm 0.4$ & $7.45 \pm 0.22$ \\
\hline Volume & $73.2 \pm 11.4$ & $76.1 \pm 9.9$ \\
\hline
\end{tabular}

* All the data are Mean \pm SD

\section{DISCUSSION}

This study assessed thestorage conditions including duration of storage ,type of storage containers used in the production of platelet concentrates at the hospital, with standard procedures set by NBTS as adopted from AABB. The study also determined quality parameters of platelet concentrates which included cell counts, $\mathrm{pH}$, and volume. These were compared with the standards set by Standards Committee of NBTS as adopted from AABB. ${ }^{4}$ Separation was achieved using a plasma extractor. However, the prolonged delays of more than five hour from the time of blood collection to start of centrifugation may affect the quality of platelet concentrates. Delayed separation may disrupt the compartments and allow the cells to mix. This may result in higher red cell contamination in the final platelet concentrate as was observed in the study. Low residual WBC counts in platelet productions are desirable in order to minimize side effects of residual leucocytes such as febrile reactions and to minimize the platelet storage lesion which can be enhanced by high leukocyte count. ${ }^{5}$ All the concentrates made up from outdoor blood donation camps in this study had high WBC contamination presumably because no hygiene was maintained during performing phlebotomy.

\section{CONCLUSION}

Our findings shows that quality of platelets and storage conditions plays an important role in quality of platelet units . There is therefore need to strengthen the quality assurance program for preparation of platelet concentrates and it is recommended that all platelet concentrates prepared should be subjected to platelet count before issue so that only those concentrates that meet quality standards are issued.

Conflicts of interest: Declared, authours have no conflict of interest

\section{Funding/Financial support:None}

\section{REFERENCES}

1. Njoroge $\mathrm{N}$ Richard, Maturi P Mwamba, Githanga J, and Jamilla Rajab, "Quality Parameters of Platelet Concentrate at Kenyatta National Hospital's Blood Transfusion Unit." International Journal of Hematological Disorders, vol. 1, no. 1 (2014): 35-40. doi: 10.12691/ijhd-1-1-7.

2. Perrota PL, Anderson KC. Blood banking and transfusion medicine - Basic Principles and Practice. Philadelphia: Churchill Livingstone; 2003. pp. 181-205.

3. Holme S. Storage and quality assessment of platelets. Vox Sang. 1998; 74: 207-16.

4. Mark $k$ fung, Anne Ederm, Steven L spitalnik; Connie M Westhoff, American association of blood bank, AABB.

5. Seghatchian MJ, Bessos $H$. Residual leucocyte in $\mathrm{BC}$ accelerates the rate of platelet storage lesion. Transfusion science 1991;159(1): 61-62. 